\title{
Engineered Breast Cancer Cell Spheroids Reproduce Biologic Properties of Solid Tumors
}

\author{
Stephanie L. Ham, Ramila Joshi, Gary D. Luker, and Hossein Tavana*
}

Solid tumors develop as 3D tissue constructs. As tumors grow larger, spatial gradients of nutrients and oxygen and inadequate diffusive supply to cells distant from vasculature develops. Hypoxia initiates signaling and transcriptional alterations to promote survival of cancer cells and generation of cancer stem cells (CSCs) that have self-renewal and tumor-initiation capabilities. Both hypoxia and CSCs are associated with resistance to therapies and tumor relapse. This study demonstrates that $3 \mathrm{D}$ cancer cell models, known as tumor spheroids, generated with a polymeric aqueous two-phase system (ATPS) technology capture these important biological processes. Similar to solid tumors, spheroids of triple negative breast cancer cells deposit major extracellular matrix proteins. The molecular analysis establishes presence of hypoxic cells in the core region and expression of CSC gene and protein markers including CD24, CD133, and Nanog. Importantly, these spheroids resist treatment with chemotherapy drugs. A combination treatment approach using a hypoxia-activated prodrug, TH-302, and a chemotherapy drug, doxorubicin, successfully targets drug resistant spheroids. This study demonstrates that ATPS spheroids recapitulate important biological and functional properties of solid tumors and provide a unique model for studies in cancer research.

\section{Introduction}

During early stages of epithelial cancers, neoplastic cells invade through the basement membrane and proliferate abnormally as $3 \mathrm{D}$ cellular masses supplied with nutrients through simple diffusion from surrounding vasculature. ${ }^{[1,2]}$ The resulting solid tumors contain phenotypically and functionally heterogeneous cells and continue to grow until availability of oxygen and nutrients to cells distant from surrounding vasculature becomes limited. ${ }^{[1-3]}$ Tumor hypoxia activates hypoxia-inducible factor (HIF) pathway by promoting protein stability of HIF- $\alpha$

\footnotetext{
S. L. Ham, R. Joshi, Prof. H. Tavana

Department of Biomedical Engineering

The University of Akron

Akron, OH 44325, USA

E-mail: tavana@uakron.edu

Prof. G. D. Luker

Department of Radiology, Microbiology and

Immunology, and Biomedical Engineering

University of Michigan

Ann Arbor, MI 48109, USA
}

DOI: 10.1002/adhm.201600644 subunits and their translocation to the nucleus. Binding of HIF transcription factors to hypoxia-responsive elements in target genes leads to activation of hundreds of genes that enable cells to adapt to low oxygen and survive in hypoxic environments. ${ }^{[4]}$ Hypoxia promotes resistance to chemotherapy and radiation therapy through mechanisms such as altered cellular metabolism and genetic instability that drive formation of drug resistant subpopulations of cells. ${ }^{[5]}$ More recent studies show that tumors often harbor cells with self-renewal and drug resistance capabilities, i.e., cancer stem cells (CSCs). ${ }^{[6,7]}$ It is known that HIF-1 expression induces expression of genes, such as a gene encoding the stem cell factor that participate in stem cell maintenance. ${ }^{[8,9]}$ Tumor hypoxia and presence of CSCs correlate with chemotherapy resistance, which is a main reason for failure of cancer treatment in patients with advanced, inoperable cancers. ${ }^{[10]}$

Widely used monolayer (2D) cell cultures permit cancer cells unrestricted access to nutrients and oxygen, unlike solid tumors. As a result, critical elements such as mechanical and biochemical signaling and intercellular communications present in tumors are absent from standard 2D cell cultures. ${ }^{[11,12]}$ To study solid tumors in vitro, it is essential to employ culture systems that preserve their biological properties. 3D cultures provide a unique tool to model tumor environments. ${ }^{[13]}$ Cancer cell spheroids present a relevant model due to their 3D structure, complex intercellular network, and restricted diffusion of nutrients and oxygen. ${ }^{[14,15]}$ Unfortunately, spheroid culture techniques face difficulties in production of consistently-sized spheroids in standard labware, ease of maintenance, drug treatment, analysis of cellular responses, and downstream molecular analysis. To facilitate routine use of spheroids, we have developed a high throughput spheroid printing microtechnology using a polymeric aqueous two-phase system (ATPS) that allows simple and quick spheroid formation in standard microwell plates. Here, we utilize triple negative breast cancer (TNBC) as a model for biological and functional characterization and drug response analysis of ATPS spheroids. TNBC is the most lethal subtype of breast cancer. Treatment options for TNBC are limited, underscoring the need for new approaches to therapy. ${ }^{[16]}$

To generate spheroids with ATPS technology, a submicroliter drop of the denser polymeric aqueous phase mixed with 
cancer cells is robotically dispensed into wells of a nonadherent microwell plate containing the immersion polymeric aqueous phase. The drop phase maintains cancer cells in close proximity and facilitates formation of a single spheroid upon incubation. The ATPS technology is adapted to standard 384 microwell plates where spheroids can easily be maintained or treated by direct addition of media or drug solutions, respectively. Additionally, drug responses can be conveniently evaluated using standard plate readers by direct addition of cellular viability reagents. We demonstrate that TNBC spheroids formed with the ATPS technology reproduce key biological properties and functionality of solid tumors including proliferation patterns, deposition of matrix proteins, hypoxia, expression of CSC markers, and drug resistance. Recapitulating these properties of tumors in vitro, coupled with the potential to incorporate other complexities of tumor microenvironment, makes the ATPS spheroid technology a unique 3D culture approach for generation of physiologically relevant tumor models for use in biological and drug screening studies.

\section{Results and Discussion}

\subsection{ATPS Microprinting of Spheroids in 384 Microwell Plates}

The ATPS spheroid technology forms a single MDA-MB-157 TNBC cell spheroid in each well of a standard 384 microwell plate within $24 \mathrm{~h}$ of incubation (Figure 1a). The key to this efficient process is the immiscibility of a $0.3 \mu \mathrm{L}$ aqueous dextran (DEX) phase drop and the immersion polyethylene glycol (PEG) phase and favorable partition of cells to the drop phase due to an ultralow interfacial tension between the two aqueous phases. ${ }^{[17-19]}$ Use of two highly aqueous phases ensures free diffusion of nutrients from the immersion phase to cells in the low-volume drop and removal of waste products of cells from the drop phase. Cancer cells restricted to the DEX phase drop spontaneously aggregate and form a spheroid. Printing MDAMB-157 spheroids with a density of $1.5 \times 10^{4}$ cells results in an average diameter of $235 \mu \mathrm{m}$ with a standard deviation of $\approx 8 \%$ from the mean within each microplate (Figure 1b) that is reproducible across different plates. The variation of diameter for individual spheroids is typical of a normal distribution (Figure 1b, inset). The ATPS approach reproducibly generates consistentlysized spheroids at different cell densities $\left(2.5 \times 10^{4}, 5.0 \times 10^{4}\right.$, and $1.0 \times 10^{5}$ shown in Figure SI-1 in the Supporting Information). While this technique is compatible with manual pipetting, the use of liquid handling robotics reduces variability and labor and increases precision and efficiency of dispensing lowvolume DEX phase drops into the aqueous PEG phase. Spheroid consistency and uniformity upon formation are critical to establish a similar metabolic activity baseline for all spheroids in a microplate and ensure that differences in metabolic activity are caused by treatment with drug compounds and not variations in size of spheroids. Once spheroids form, they are conveniently maintained by direct addition of fresh media to the wells. The addition reduces concentrations of polymers below minimum concentrations required for maintaining a two-phase system and converts the ATPS to a single media phase. Therefore, ATPS is solely used as a patterning medium to generate spheroids. Micropatterning with ATPS has additionally facilitated the generation of cancer cell niches for migration studies. ${ }^{[2,21]}$

\subsection{Evaluation of Cell Viability of Spheroids}

We used a standard PrestoBlue assay to quantify viability of ATPS spheroids since it is a one-step addition assay that eradicates the need for multiple wash steps or transfer of spheroids to special plates for viability analysis. PrestoBlue primarily has been used with 2D cultures, producing viability data similar to the conventional XTT (sodium 3'-[1-(phenyl amino-carbonyl)3,4-tetrazolium]-bis-[4-methoxy-6-nitro] benzene sulfonic acid hydrate) assay. ${ }^{[22]}$ Spheroids of four different cell densities $\left(1.5 \times 10^{4}, 2.5 \times 10^{4}, 5.0 \times 10^{4}\right.$, and $\left.1.0 \times 10^{5}\right)$ were formed in a 384 well plate and incubated with PrestoBlue. The media fluorescent intensity due to the reduction of resazurin to resorufin 

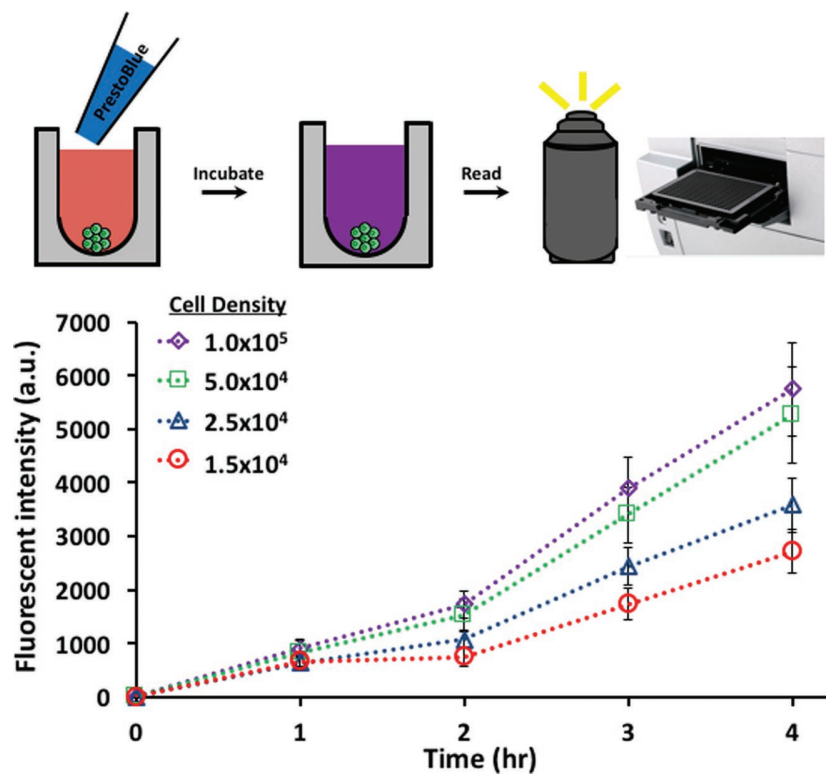

Figure 2. Optimization of PrestoBlue assay to determine viability of cells in spheroid cultures. PrestoBlue is directly added to wells containing spheroids and metabolized by live cells. Based on the cellular metabolic activity, the solution emits a fluorescence signal detectable with standard plate readers. Incubation of spheroids with PrestoBlue for 3-4 h optimally resolves cell viability.

by metabolically active cells was measured for all four spheroid densities every hour for $4 \mathrm{~h}$ (Figure 2). Between incubation time points of 2 and $3 \mathrm{~h}$, the fluorescent signal became significantly different within each group, i.e., spheroids of the same cell density. With longer incubation time, the fluorescent signal differences became more pronounced. Based on a statistical analysis, it was validated that 3-4 h of incubation was optimal to measure cell viability of spheroids. Slower diffusion of the resazurin component into spheroids is most likely the reason for the longer incubation time compared to 2D cultures. Incubations longer than $4 \mathrm{~h}$ resulted in insignificant changes of the fluorescent signal within each group due to saturation. Thus, this test provided an optimal incubation time to evaluate cell viability of drug treated spheroids below. Our previous work also validated that the use of PrestoBlue allows us to sensitively detect increases in the fluorescent signal intensity from growing spheroids during long-term cultures. ${ }^{[23]}$

\subsection{Extracellular Matrix Deposition of Spheroids}

Cryosections of MDA-MB-157 spheroids were stained with hematoxylin and eosin ( $\mathrm{H} \& \mathrm{E})$ to examine their interior morphology. This staining showed a highly compact and dense cellular network without any gaps (Figure 3a), similar to a previous study that reports TNBC patient tumors to be highly cellularized and compact with a low fraction of extravascular and extracellular space. ${ }^{[24]}$ Next, cryosections were immunostained for extracellular matrix (ECM) proteins type I collagen, laminin, and fibronectin. MDA-MB-157 spheroids of smaller cell density $\left(1.5 \times 10^{4}\right)$ showed expression of all three proteins, with (a)
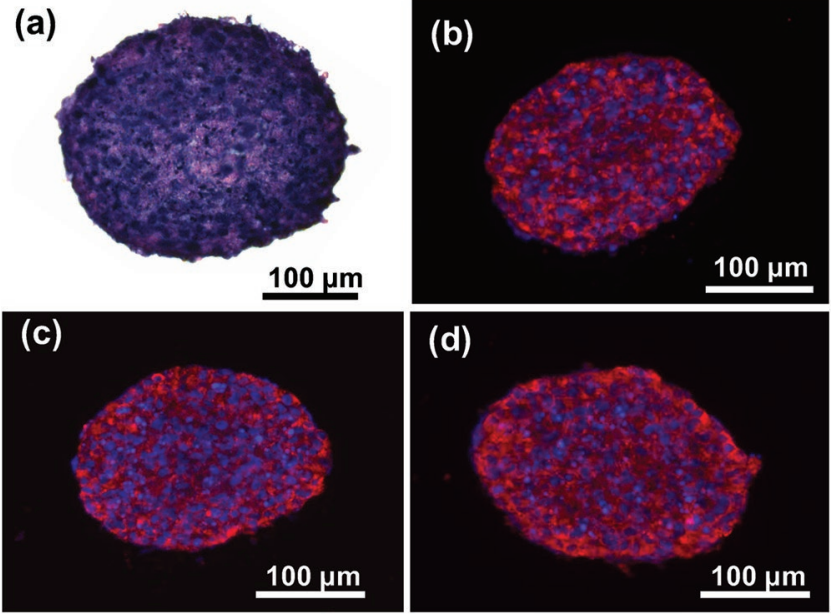

Figure 3. a) H\&E staining of a $1.5 \times 10^{4}$ cell density MDA-MB-157 spheroid shows a compact intercellular network. Blue and purple represent nuclei and cytoplasm, respectively. Immunohistochemical analysis for ECM proteins (shown in red) show deposition of b) collagen I, c) fibronectin, and d) laminin in ATPS spheroids. Blue represents nuclei staining with Hoechst.

greater abundance of collagen I and laminin (Figure 3b-d). Cell-ECM interactions play major roles in the tumor microenvironment. ${ }^{[25]}$ Studies show that expression of both collagen I and fibronectin is elevated in breast cancer and associated with the tumor formation process. ${ }^{[25,26]}$ Laminin is also highly expressed in invasive breast cancers and promotes cell migration, a process fundamental to metastasis. ${ }^{[26]}$ The expression of ECM proteins is implicated in drug and radiation resistance of breast cancer cells. ${ }^{[26,27]}$ Therefore, ATPS spheroids display critical cell-matrix interactions. Interestingly, larger density spheroids of MDA-MB-157 cells $\left(1.0 \times 10^{5}\right)$ showed lower expression of ECM proteins in the inner core cancer cells (Figure SI-2, Supporting Information), suggesting reduced activity of these cells due to limited nutrients and oxygen.

\subsection{Spheroid Size Dependent Proliferation and Hypoxia}

We immunostained cryosections of MDA-MB-157 spheroids formed with $1.5 \times 10^{4}$ and $1.0 \times 10^{5}$ cells for the cell proliferation marker Ki-67. This staining showed differential distribution of proliferative cells. In smaller spheroids, proliferative cells were distributed homogenously throughout the spheroid (Figure 4a). By comparison, proliferative cells in larger spheroids were mainly present toward the periphery of the spheroid (Figure 4b). Quantitative analysis of distribution of Ki-67+ cells confirmed this observation (Figure 4). Considering the average radius of large spheroids $(220 \pm 22 \mu \mathrm{m})$, it is likely that diffusion limitations of nutrients and oxygen to cells residing in the core zone retards their proliferative activities. This is consistent with suggested free diffusion distance of 150-200 $\mu \mathrm{m} .{ }^{[28]}$ Smaller sized spheroids with a radius of $118 \pm 11 \mu \mathrm{m}$ allow free diffusive molecular transport to support cellular proliferation in the central zone. Another potential cause for the lack of Ki- $67^{+}$ cells in the core region of large spheroids is greater consumption of nutrients and oxygen by densely packed cells at the 


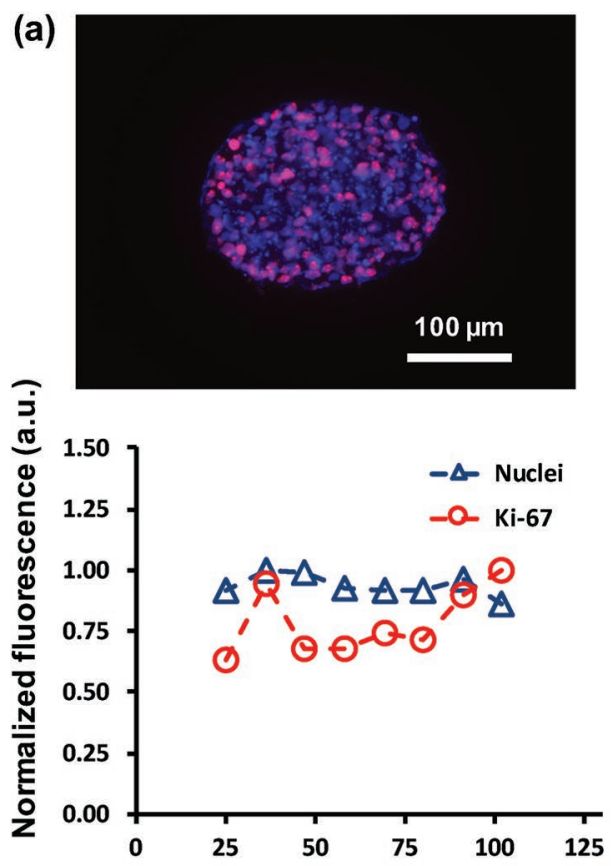

Distance from center $(\mu \mathrm{m})$

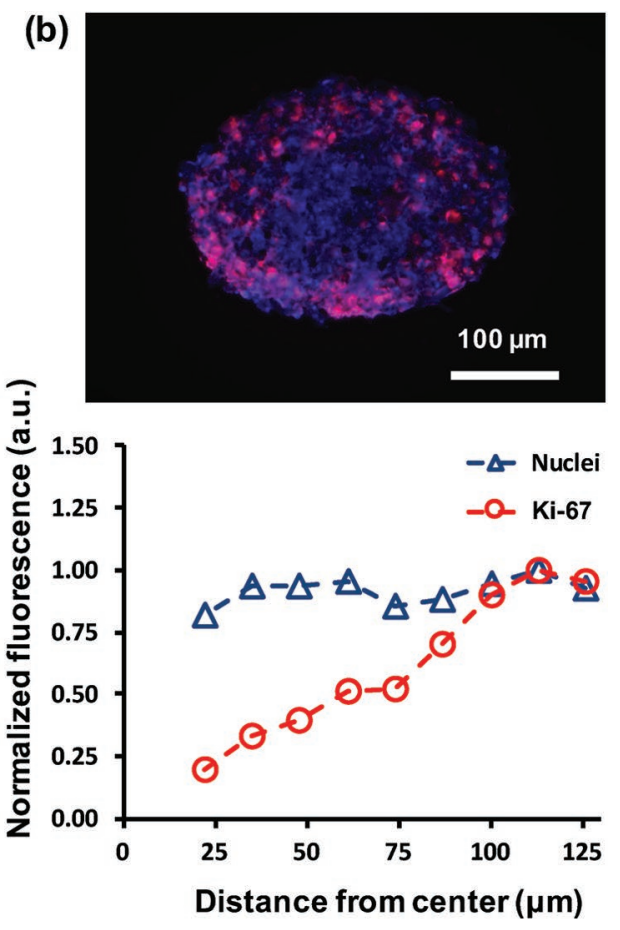

Figure 4. Immunostained cryosections of a) $1.5 \times 10^{4}$ and b) $1.0 \times 10^{5}$ cell density spheroids show the distribution of Ki-67 positive (pink) proliferative cells. Analysis of stained sections is used to compare the distribution of nuclei (blue) and proliferative cells throughout each section. The larger spheroid contains a nonuniform distribution of proliferative cells compared to the smaller spheroid.

peripheral zone. Unlike several other cancer cells we have used, MDA-MB-157 cells are tightly packed within spheroids, evident from the H\&E staining result (Figure 3a). Therefore, in addition to limited diffusive transport, close intercellular contacts and packing of cancer cells within spheroids and consumption of available oxygen and nutrients by cells in peripheral layers is a potential cause of lack of proliferative activity in the core region. Assuming a spherical shape for spheroids, $85 \%$ of cells in the large spheroids reside in a spherical shell defined by the radii of $1.5 \times 10^{4}$ and $1.0 \times 10^{5}$ cell spheroids, supporting the above explanation. Nonuniform distribution of proliferative cells is reminiscent of solid tumors with poor vascularization. ${ }^{[29]}$

The disparity between oxygen demand and consumption of cancer cells in solid tumors generates hypoxia. ${ }^{[30]}$ Tumor hypoxia has been implicated in processes including cancer cell survival, resistance to cell death, tumor angiogenesis, invasion, metastasis, radioresistance, and chemoresistance. Hypoxic regions occur more commonly in TNBC than other molecular subtypes of this disease. ${ }^{[28,31-33]}$ Therefore, we investigated whether hypoxia could account for lack of cell proliferation in the core of the large TNBC spheroids. We used an exogenous 2-nitroimidazole probe, pimonidazole, that binds covalently to $\mathrm{SH}$-containing molecules (thiols) in hypoxic tissues with less than $10 \mathrm{mmHg}$ of oxygen partial pressure. ${ }^{[28,33]}$ Cryosections of large TNBC spheroids stained positive in their core region (Figure 5a), whereas smaller spheroids lacked pimonidazole staining (Figure 5b). We further validated this result by measuring an endogenous transcriptional target of hypoxia-inducible factor-1 (HIF-1), carbonic anhydrase IX (CA IX). CA IX is a surrogate hypoxia marker, regulator of $\mathrm{pH}$ of the tumor microenvironment, and a prognostic factor found significantly more in basal-like breast tumors. ${ }^{[34,35]}$ Our q-PCR analysis showed that large TNBC spheroids display a 39.2-fold
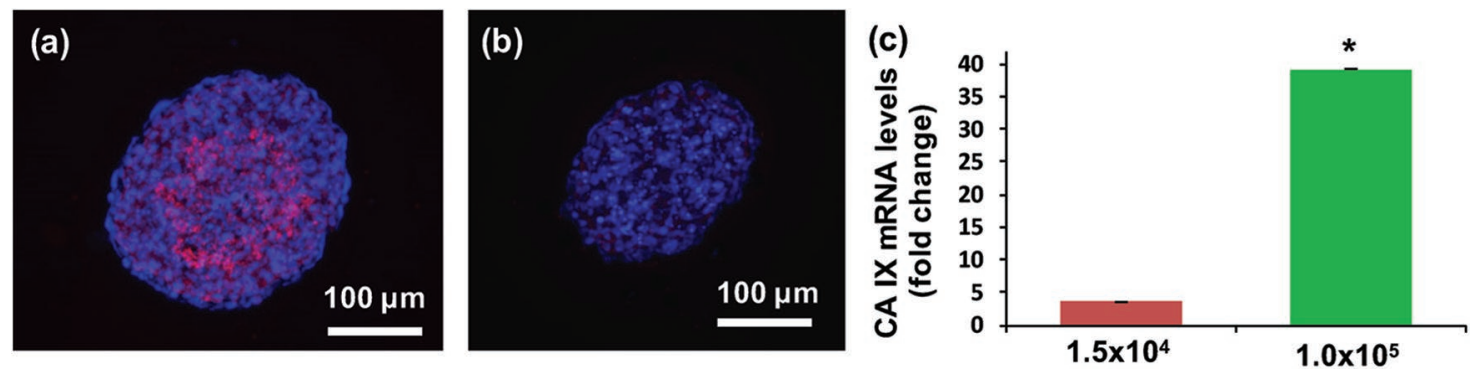

Figure 5. Pimonidazole staining (pink) of cryosections of a) $1.0 \times 10^{5}$ and b) $1.5 \times 10^{4}$ cell density spheroids of MDA-MB-157 shows presence of a hypoxic core only in the larger spheroid. c) q-PCR analysis of expression of the hypoxic marker CA IX in cells of both spheroids validates the results of immunostaining. mRNA levels are normalized with respect to a monolayer of MDA-MB-157 cells. Error bars represent the standard error of mean for three trials. Blue represents nuclei staining with Hoechst. (* $p<0.01$ ). 
change in CA IX gene expression compared to smaller spheroids with only a 3.6-fold change (Figure $5 \mathrm{c}$ ). These results are consistent with cell proliferation patterns based on Ki-67 staining and explain the lack of proliferative activity. Considering slow cycling cells and activity of pro-survival pathways under hypoxic conditions, ${ }^{[36]}$ the use of ATPS spheroids provides an opportunity to study hypoxia-mediated drug responses of cancer cells with a biologically relevant tumor model and without inducing systemic atmospheric oxygen deficiency in culture which is the current standard to generate hypoxia.

\subsection{Drug Resistance of Hypoxic Spheroids}

MDA-MB-157 spheroids of both $1.5 \times 10^{4}$ and $1.0 \times 10^{5}$ cell densities were treated with varying concentrations of doxorubicin, a standard chemotherapeutic drug currently used for TNBC treatment (Figure 6a). ${ }^{[37]}$ Spheroids showed a sigmoidal response to doxorubicin treatment; however, the larger spheroids displayed drug resistance. With a tenfold higher $\mathrm{IC}_{50}\left(481 \times 10^{-9} \mathrm{M}\right)$, the resulting cell viability of larger spheroids was much higher. The largest difference was a percent viability of $42 \%$ that occurred at a drug concentration of $100 \times 10^{-9} \mathrm{M}$. Doxorubicin resistance of larger spheroids persisted at higher concentrations. First, we utilized the natural red fluorescence of doxorubicin to evaluate whether insufficient penetration of the drug into spheroids caused the observed resistance. ${ }^{[2]}$ Fluorescent imaging of spheroids after $48 \mathrm{~h}$ of incubation with doxorubicin revealed a homogenous drug distribution within spheroids of both densities and a similar maximum signal intensity (Figure $6 \mathrm{~b}, \mathrm{c}$ ) and presence of doxorubicin in the nuclei of cells (Figure 6d). This indicated that drug resistance of larger spheroids was not due to limited drug penetration.

Next, we asked whether hypoxia in larger spheroids mediates drug resistance. Hypoxic cells may show resistance to anticancer drugs for several reasons, including reduced proliferation and metabolism due to insufficient oxygen and nutrients, lost sensitivity to p53-mediated apoptosis and consequent reduced sensitivity to certain drugs, and activation of genes involved in drug resistance including multidrug resistance 1 gene that encodes P-glycoprotein, acting as an efflux pump to reduce intracellular concentrations of some drugs. ${ }^{[10,28,33,38-43]}$ We used a hypoxia activated prodrug, TH-302, that has progressed to clinical studies. ${ }^{[4]}$ TH-302 is reduced under hypoxic conditions, (a)

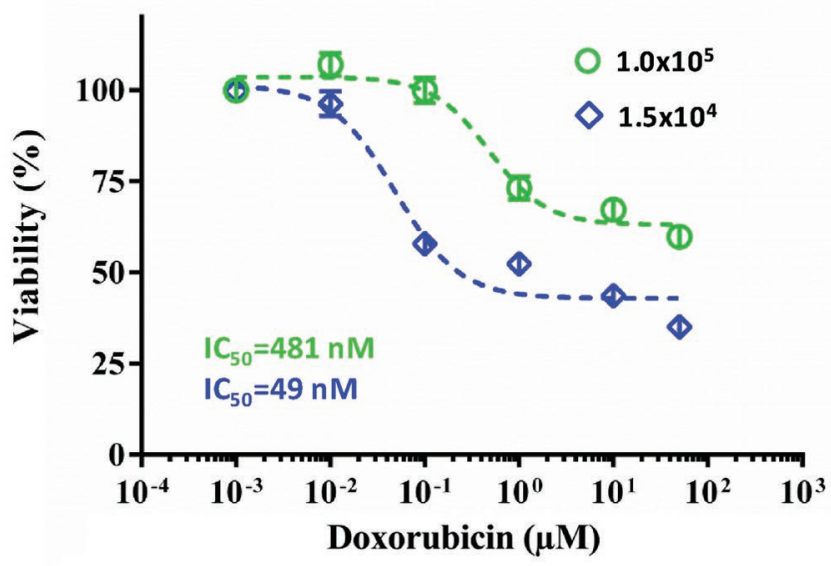

(b)

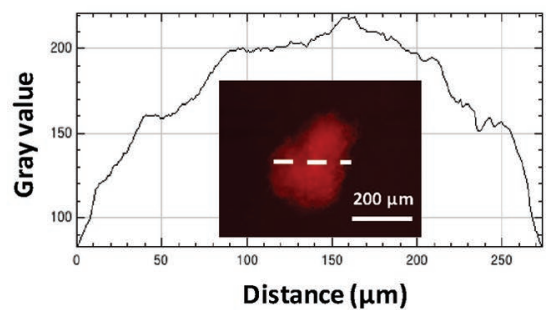

(c)

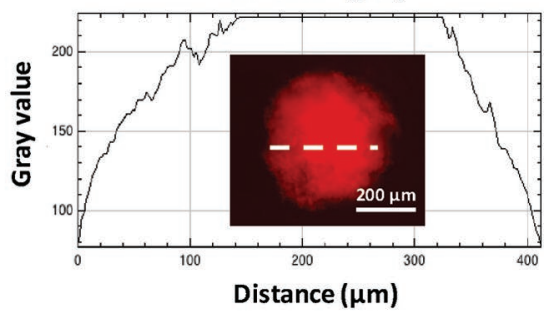

(d)
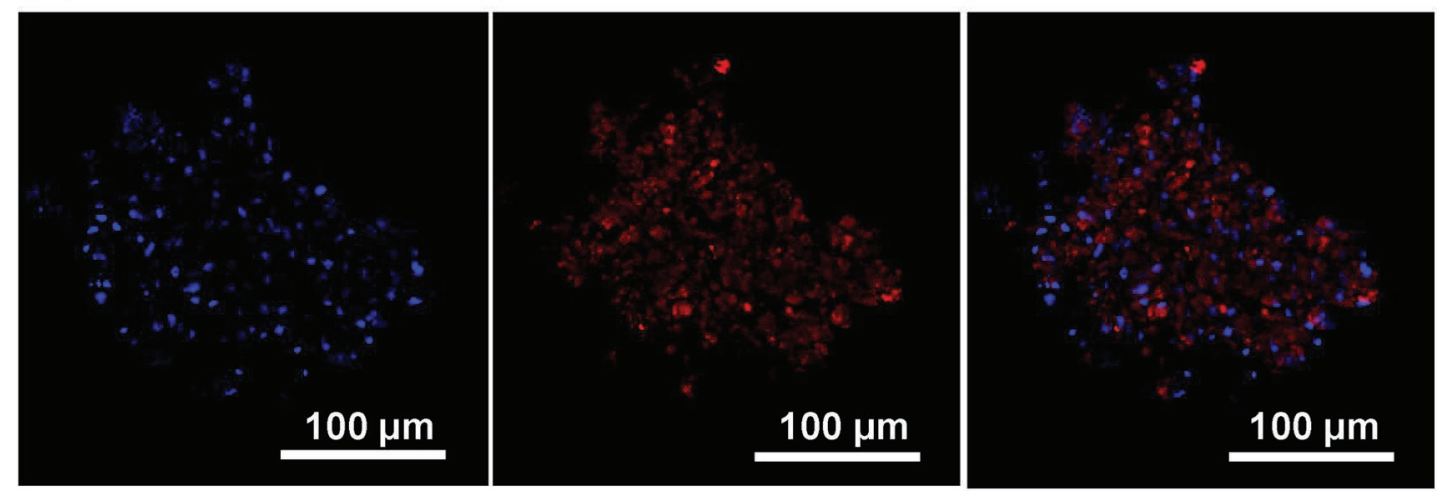

Figure 6. a) Dose-response of $1.5 \times 10^{4}$ and $1.0 \times 10^{5}$ cell density MDA-MB-157 spheroids to doxorubicin treatment shows drug resistance of larger spheroids. Error bars represent the standard error of mean. b,c) Gray values of fluorescence intensity measurements along a sample line crossing spheroids of both densities show penetration of doxorubicin into spheroids after $48 \mathrm{~h}$ of incubation. d) Doxorubicin localization in the nuclei of $1.0 \times 10^{5}$ cell density spheroids after $48 \mathrm{~h}$ of treatment. Blue represents nuclei staining with Hoechst. 


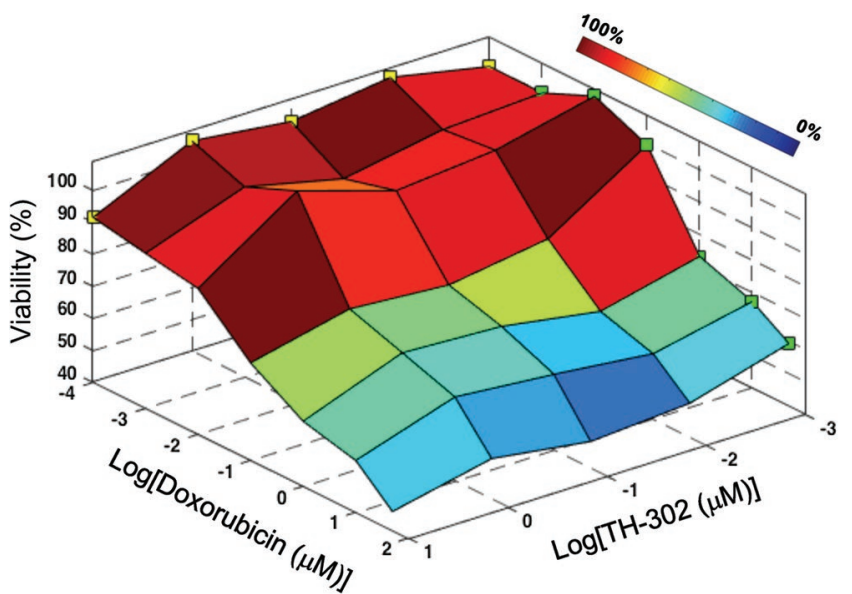

Figure 7. Surface plot of viability of $1.0 \times 10^{5}$ cell density spheroids of MDA-MB-157 cells co-treated with varying concentrations of doxorubicin and $\mathrm{TH}-302$ shows synergistic enhancement in toxicity due to combination treatment. Color bar represents the cell viability range. Green and yellow squares represent cell viability of spheroids from treatment with doxorubicin only and $\mathrm{TH}-302$ only, respectively.

releasing a DNA crosslinker bromo-isophosphoramide mustard. ${ }^{[45]}$ This mechanism of TH-302 allows selective drug activation in hypoxic cells in a tumor and has shown hypoxia-induced cytotoxicity against 32 human cancer cell lines. ${ }^{[4]}$ Larger spheroids were co-treated with doxorubicin and TH-302 over wide range of concentrations for each compound. We note that only the larger (hypoxic) spheroids were co-treated due to the hypoxia-dependent mechanism of TH-302. Consistent with previous studies, TH-302 alone at the concentrations used was ineffective. ${ }^{[4,46]}$ However, a major reduction in drug resistance was observed at $100 \times 10^{-9} \mathrm{M}$ doxorubicin with increasing TH-302 concentration (Figure 7), suggesting that these compounds synergistically target cancer cells. The greatest effect was $\approx 30 \%$ reduced cell viability with combination treatment, i.e., $70.4 \%$ viability at $10 \times 10^{-6} \mathrm{M} \mathrm{TH}-302 / 100 \times 10^{-9} \mathrm{M}$ doxorubicin compared to $99.9 \%$ viability with $100 \times 10^{-9} \mathrm{M}$ doxorubicin treatment alone, at which the largest drug resistance was observed (see Figure 6). The $10 \times 10^{-6} \mathrm{M} \mathrm{TH}-302 / 100 \times 10^{-9} \mathrm{M}$ doxorubicin combination of compounds was synergistic since the viability of co-treated larger spheroids $(70.4 \%)$ was much lower than the viability data from treatment with each single compound $\left(91.6 \%\right.$ at $10 \times 10^{-6} \mathrm{M} \mathrm{TH}-302$ and $99.9 \%$ at $100 \times 10^{-9} \mathrm{M}$ doxorubicin). We further validated synergism between the two compounds by calculating a combination index (CI), which is a quantitative measure where values smaller than unity indicate synergism, using CompuSyn software. ${ }^{[47]}$ The $10 \times 10^{-6} \mathrm{M}$ $\mathrm{TH}-302 / 100 \times 10^{-9} \mathrm{M}$ doxorubicin pair resulted in a CI value of 0.02 , demonstrating highly synergistic effects of the two drugs.

This screening approach allows identifying an optimal pair of concentrations of the cytotoxic compound to target proliferating cells and hypoxia-activated drug to target hypoxic cells. A similar result was found with a combination of a chemopreventive agent (silibinin) and doxorubicin in which specific drug concentrations of $100 \times 10^{-6} \mathrm{M}$ silibinin/25 $\times 10^{-9} \mathrm{M}$ doxorubicin produced a synergistic effect in breast cancer cells. ${ }^{[48]}$ Our result is also consistent with a few other studies, including a phase II clinical trial, that demonstrated synergistic effects of
TH-302 combined with chemotherapy and radiotherapy treatments against cancer cells. ${ }^{[45,49-51]}$ The enhanced efficacy of doxorubicin at a low concentration of $100 \times 10^{-9} \mathrm{M}$ by addition of $10 \times 10^{-6} \mathrm{M}$ TH-302 is also advantageous from a practical standpoint to prevent/reduce cardiotoxic side effects. ${ }^{[52,53]}$ Therefore, ATPS spheroids offer solid tumor models to identify effective drug combinations that reduce/overcome cancer cell resistance to chemotherapeutics.

We note that the combination of $\mathrm{TH}-302$ and doxorubicin did not drop cell viability to that of $1.5 \times 10^{4}$ cell density spheroids, i.e., $52.2 \%$, at $100 \times 10^{-9} \mathrm{M}$ doxorubicin (diamonds in Figure $6 \mathrm{a}$ ). This is potentially from the limited potency of the TH-302 compound and the involvement of additional mechanisms of resistance, such as the inoculum effect, which causes reduced cytotoxic activity of a chemotherapy drug as the cancer cell density increases. ${ }^{[54]}$ The inoculum effect with doxorubicin results from insufficient number of drug molecules at high cell densities, causing a decreased drug accumulation in cancer cells. ${ }^{[54,55]}$ For example, increasing the density of cancer cells resulted in a 27 -fold decrease in the $\mathrm{LD}_{50}$ of doxorubicin against lymphoma cells ${ }^{[56]}$ and 40 times lower growth-inhibitory capabilities (when comparing $\mathrm{LD}_{50}$ values) in leukemia cells. ${ }^{[55]}$ Increasing doxorubicin concentrations substantially reduced this effect. ${ }^{[54]}$ Our results also show that combination of $10 \times 10^{-6} \mathrm{M} \mathrm{TH}-302$ and $50 \times 10^{-6} \mathrm{M}$ doxorubicin reduces the cell viability to $45.9 \%$, i.e., $\approx 26 \%$ further decrease compared to the $10 \times 10^{-6} \mathrm{M} \mathrm{TH}-302 / 100 \times 10^{-9} \mathrm{M}$ doxorubicin pair and suggesting that the inoculum effect plays a role in doxorubicin resistance of MDA-MB-157 spheroids. Nevertheless, this cell viability is still greater than that of the $1.5 \times 10^{4}$ cell density spheroids at a similar doxorubicin concentration (see Figure 6), indicating that doxorubicin resistance is caused, at least in part, by hypoxia.

Previous studies showed that unlike with doxorubicin, the inoculum effect was not observed with cisplatin at various cell densities. ${ }^{[55,56]}$ Therefore, we treated small and large spheroids of MDA-MB-157 cells with varying concentrations of cisplatin and determined cellular viability. Large spheroids still displayed resistance at effective concentrations of the drug and displayed $\approx 35 \%$ greater viability than the small spheroids (Figure 8 ). Collectively, our results indicate that the hypoxia in large spheroids has a major influence on drug resistance of breast cancer cells in the absence of the inoculum effect, and that other phenomena such as the inoculum effect with certain chemotherapeutics and limited potency of TH-302 contribute to the observed doxorubicin resistance. A detailed study is required to distinguish between such effects.

\subsection{Cancer Stem Cell Markers in Hypoxic Spheroids}

Hypoxia in solid tumors is associated with stem cell-like cancer cells with tumor initiation, recurrence, and metastasis capacity. ${ }^{[57-62]}$ It has been shown that hypoxic environments house stem cells because of their preference for low oxidative DNA damage, ${ }^{[57]}$ and that CSCs rely on hypoxia induced factors for survival and self-renewal. ${ }^{[58]}$ Chemotherapies typically kill the majority of cancer cells in tumors, but CSCs are able to evade therapy due to their resistance mechanisms. ${ }^{[63]}$ The 


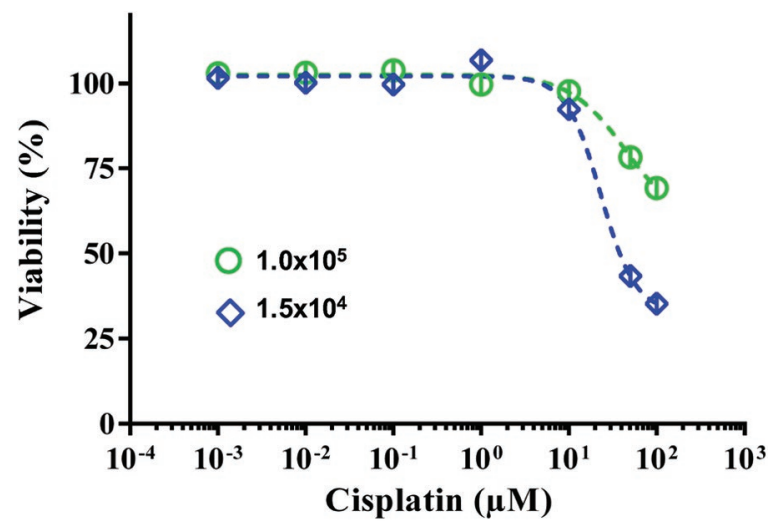

Figure 8. Dose-response of MDA-MB-157 spheroids made with $1.0 \times$ $10^{5}$ and $1.5 \times 10^{4}$ cells to cisplatin treatment. Error bars represent the standard error of mean.

consequent survival of self-renewing CSCs causes recurrence of cancer. ${ }^{\left[{ }^{[3]}\right]}$ To evaluate whether hypoxic tumor spheroids present stem cell markers and the utility of ATPS spheroids to study CSCs, we performed a gene expression study of breast CSC markers CD24, CD44, CD133 (prominin-1), ALDH1, and $\alpha_{6}$ integrin, and pluripotency markers Oct4, Sox2, and Nanog. ${ }^{[64]}$ This analysis was done in parallel with $1.5 \times 10^{4}$ and $1.0 \times 10^{5}$ cell density spheroids of MDA-MB-157 cells, and resulting mRNA levels were normalized to that of a normoxic monolayer of cells for each gene marker. Among these markers, CD24,
CD133, and Nanog showed greater expression in hypoxic, $1.0 \times 10^{5}$ cell density spheroids (Figure 9a-c). Other markers either showed similar expression in both spheroids or lower expression than the monolayer of cells (Figure SI-3, Supporting Information). Increased expression of CD24 and CD133 in hypoxic spheroids was additionally confirmed at the protein level using immunostained cryosections (Figure 9d,e). Thus, our data suggests an association between hypoxia in the MDAMB-157 TNBC spheroids and upregulated activity of these stem cell markers.

Breast tumor cells with CD44 ${ }^{\text {high }} / \mathrm{CD} 24^{\text {low }}$ surface markers expression were first proposed as breast CSCs with high tumorigenic capacity ${ }^{[65]}$ and subsequently validated in other studies. ${ }^{[66-69]}$ Nevertheless, growing evidence suggests heterogeneity in populations of CSCs and that breast CSCs cannot be stratified using this marker only. ${ }^{[70,71]}$ Examining metastatic deposits of mammary tumors showed variable expression of CSC markers in different tumor samples and lack of CD44 expression in about one-third of tumor samples but expression of other CSC markers in these cells. ${ }^{[72]}$ Elevated levels of CD24 alone correlated with advanced disease stages in several types of human epithelial cancers including breast cancer and increasing tumor grade and malignancy. ${ }^{[73,74]}$ Recent studies also show that hypoxia promotes CD24 expression ${ }^{[75,76]}$ and that $\mathrm{CD} 44^{-} / \mathrm{CD} 24^{+}$phenotype predicts poor outcome. ${ }^{[67,77,78]}$ Furthermore, expression of the transmembrane glycoprotein CD133 in primary breast tumors and breast cancer cell lines has been associated with self-renewal of cells, ${ }^{[79]}$ tumor (a) CD24

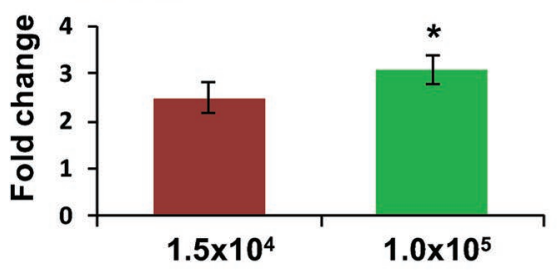

(d)

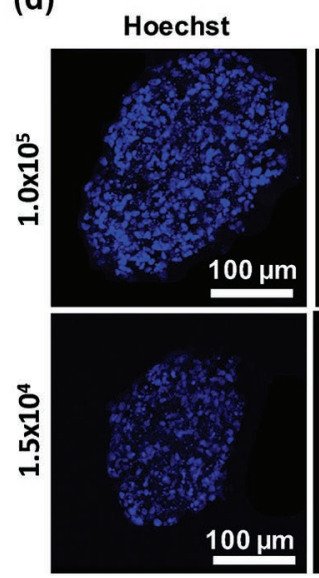

(b) CD133

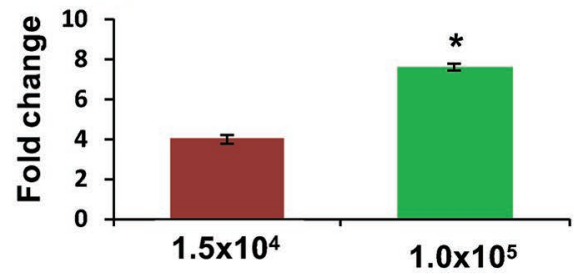

(e)

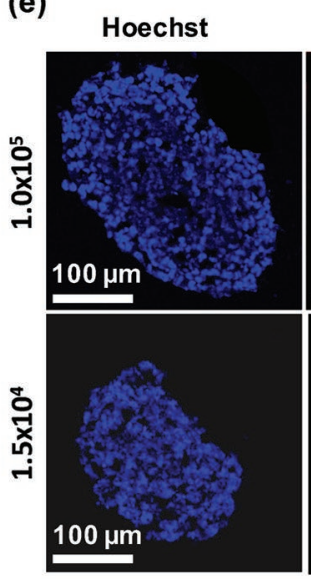

(c) Nanog

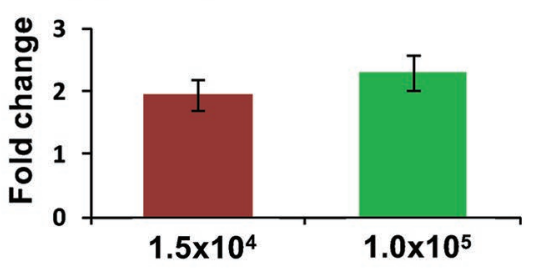

Figure 9. q-PCR analysis of expression of a) CD24, b) CD133, and c) Nanog in $1.5 \times 10^{4}$ and $1.0 \times 10^{5}$ cell density spheroids of MDA-MB-157 cells normalized against mRNA levels of a monolayer of cells. Expression levels are relative to $\beta$-actin and $H P R T$ and calculated using the $\Delta \Delta \mathrm{C}_{\mathrm{t}}$ method. Fold change in mRNA expression represent $2^{-\Delta \Delta C t}$. Error bars represent the standard error of mean for three trials. Largest cryosections of $1.5 \times 10^{4}$ and $1.0 \times 10^{5}$ cell density spheroids immunostained for cancer stem cell markers d) CD24 (green) and e) CD133 (red). Blue represents nuclei staining with Hoechst. (*p<0.05). 
size and grade, ${ }^{[80]}$ tumor angiogenesis, ${ }^{[81,82]}$ invasiveness, ${ }^{[83]}$ and metastasis. ${ }^{\left[{ }^{[4]}\right.}$ Targeting CD133 prevents local tumor recurrence in mouse models of breast cancer. ${ }^{[85,86]}$ Therefore, expression of CD24 and CD133, but not CD44, in MDA-MB-157 tumor spheroids in our study is consistent with these findings and agrees with identified variability in CSC markers among different lines of breast cancer cells. ${ }^{[87]}$ Expression of embryonic stem cell pluripotency markers Sox2, Oct4, and Nanog has also been reported in poorly differentiated breast cancer cells and associated with poor clinical outcome, ${ }^{[88-90]}$ suggesting that regulatory networks controlling the function of stem cells may also be active in breast tumors. Recent studies show that hypoxia leads to transcriptional activation of the gene encoding Nanog in breast CSCs and Nanog-expressing cells present tumor initiation capacity in NSG mice. ${ }^{[6,91,92]}$ Overall, this study suggests association of hypoxia and CSCs in TNBC spheroids and that the ATPS technology provides a useful tumor model for future studies of CSCs and heterogeneity of these cells in distinct environments.

\section{Conclusions}

The ATPS microprinting approach enabled convenient production of spheroids of well-defined size in standard 384 microwell plates and drug treatment and downstream biochemical analysis of cellular responses in the same plate. Resulting spheroids reproduced key properties of solid tumors including compact morphology and deposition of major ECM proteins. Increase in cell density of spheroids resulted in a preferential cell proliferation close to the periphery of spheroids and hypoxia in the core region, indicating consumption of extracellular oxygen by tightly packed layers of cells at the peripheral zone. Hypoxic spheroids showed resistance to a standard chemotherapy drug (doxorubicin) over a wide concentration range. Imaging of drug diffusion into spheroids eliminated widely proposed diffusion limitations as the cause of resistance and emphasized a major role for hypoxia. A combination treatment of hypoxic spheroids with doxorubicin and a hypoxia-activated prodrug (TH-302) significantly reduced drug resistance, suggesting a potential strategy against multidrug resistance in tumors. Hypoxia in tumor spheroids was accompanied by the expression of several genes associated with breast cancer stem cells. Altogether, these findings demonstrated the utility of aqueous two-phase tumor spheroids in cancer research to develop biomimetic tumor models that exhibit key biological and functional properties of solid tumors such as hypoxia and drug resistance, and present a tool to study cancer stem cells.

\section{Experimental Section}

ATPS Preparation: BioUltra PEG (Sigma), Mw: $35000 \mathrm{Da}$, and DEX (Pharmacosmos), Mw: $500000 \mathrm{Da}$, were used to form an ATPS due to their biocompatibility. ${ }^{[93]}$ PEG and DEX were prepared in complete cell culture media at $5 \%(\mathrm{w} / \mathrm{v})$ and $12.8 \%(\mathrm{w} / \mathrm{v})$, respectively. The polymer solutions were vortexed and then kept in a $37{ }^{\circ} \mathrm{C}$ water bath for $1 \mathrm{~h}$ to ensure complete dissolution. The PEG phase solution was filtered with a $0.2 \mu \mathrm{m}$ filter to remove any impurities. Both polymer solutions were then stored at $4{ }^{\circ} \mathrm{C}$ until use.
Cell Culture: Prior to spheroid formation, MDA-MB-157 TNBC cells were grown in $\mathrm{T} 175$ flasks at $37^{\circ} \mathrm{C}$ and $5 \% \mathrm{CO}_{2}$ to a confluent monolayer. Cells were cultured in Dulbecco's Modified Eagle Medium (Sigma) supplemented with 10\% fetal bovine serum (Sigma), 1\% glutamine (Life Technologies), and 1\% antibiotic (Life Technologies). Once confluent, cells were rinsed with phosphate buffered saline (PBS) and dissociated by incubating with $5 \mathrm{~mL}$ of trypsin for $\approx 7 \mathrm{~min}$. The cells were collected and neutralized with $10 \mathrm{~mL}$ of complete medium, and centrifuged down for $5 \mathrm{~min}$ at $1000 \mathrm{rpm}$. The supernatant was removed and the cells were resuspended in $1 \mathrm{~mL}$ of medium for counting with a hemocytometer.

Spheroid Formation Using ATPS: A 384 well plate (destination plate) for spheroid formation was prepared by adding $30 \mu \mathrm{L}$ of the immersion PEG phase to each well. The DEX phase was mixed at an equal volume with the MDA-MB-157 cell suspension at a density of $3.0 \times 10^{4}$ or $2.0 \times 10^{5}$ cells per $0.3 \mu \mathrm{L}$. The addition of the DEX phase solution to these cell suspensions diluted DEX concentration to $6.4 \%(\mathrm{w} / \mathrm{v})$ and adjusted the cell densities to $1.5 \times 10^{4}$ and $1.0 \times 10^{5}$ cells per $0.3 \mu \mathrm{L}$. Each well from a column of a 384 well plate (source plate) was filled with $\approx 20 \mu \mathrm{L}$ of the aqueous DEX phase containing cells. A liquid handling robot (Bravo SRT, Agilent) was used to mix the content of the wells of the source plate and then aspirate $0.3 \mu \mathrm{L}$ from each well. ${ }^{[94]}$ Then the solution was dispensed as a single drop into each well of one column of the PEC phase-containing destination plate. This process was repeated for all columns of the destination plate, which was then placed in an incubator. Within $24 \mathrm{~h}$ of incubation, a single spheroid of MDA-MB-157 cells formed in each well.

Evaluation of Viability of Spheroids: A standard cellular metabolic activity detection assay (PrestoBlue) was utilized to determine the viability of spheroids. Metabolically active and viable cells reduce the resazurin compound in PrestoBlue, producing fluorescence detectable with a standard plate reader. Since the PrestoBlue assay had only been optimized by the manufacturer for monolayer cultures, the required incubation time was adjusted for 3D spheroid cultures. This was determined by forming MDA-MB-157 spheroids of $1.5 \times 10^{4}, 2.5 \times 10^{4}$, $5.0 \times 10^{4}$, and $1.0 \times 10^{5}$ cell density, adding the PrestoBlue reagent at $10 \%$ of total well volume, and measuring their fluorescent signal at different time points. The different cell density spheroids were generated using the ATPS approach with a cell culture media renewal at $24 \mathrm{~h}$ and maintaining cultures for an additional $24 \mathrm{~h}$ prior to viability evaluation. Based on this optimization study, an incubation period was selected that produced a significant difference in the fluorescent signal among different sizes of spheroids.

Histological Examination of Spheroids: To perform histological examination, a previously established spheroid cryosectioning protocol was adapted. ${ }^{[95]}$ First, three-day old MDA-MB-157 spheroids were gently pipetted from wells into $200 \mu \mathrm{L}$ microcentrifuge tubes. Supernatant media transferred with spheroids was removed from tubes. Spheroids were fixed with $100 \mu \mathrm{L}$ of $4 \%$ formaldehyde for $10 \mathrm{~min}$ at room temperature. Following fixation, the spheroids were gently rinsed with $100 \mu \mathrm{L}$ of PBS three times for $5 \mathrm{~min}$. Spheroids were then incubated with $100 \mu \mathrm{L}$ of $30 \%(\mathrm{w} / \mathrm{v})$ sucrose solution at $4{ }^{\circ} \mathrm{C}$ until they sank to the bottom of the microcentrifuge tubes. This ensured water removal from spheroids and prevented crystal formation upon freezing. Next, an equal volume $(100 \mu \mathrm{L})$ of a tissue freezing medium (Triangle Biomedical Sciences) was added to each tube and incubated at $4{ }^{\circ} \mathrm{C}$ overnight. The next day, cryomolds were prepared by flash-freezing with dry ice a thin layer of the tissue freezing medium in biopsy-sized cryomolds. Spheroids were then pipetted from the microcentrifuge tubes and dispensed onto the layer of the tissue freezing medium in the cryomold. The frozen layer of the medium was slightly melted at room temperature prior to mixing with the newly added medium containing the spheroid sample. It was important in this process to avoid bubble formation in the medium that would cause hole formation when cryosectioning. Once the tissue embedding medium was homogenous, a fresh second layer was added to the mold to immerse the spheroid sample, which then was flash frozen on dry ice to form frozen molds. Frozen molds containing spheroid samples were stored at $-80^{\circ} \mathrm{C}$ until use. A cryostat was used to section the samples to $10 \mu \mathrm{m}$ thick slices. The slices were transferred 
onto Superfrost Plus microscopic slides (Fisher) upon sectioning. Sections were stained with H\&E to examine spheroid morphology and immunostained following standard procedures for specific markers such as a cell proliferation protein marker (Ki-67, Cell Signaling), hypoxia (pimonidazole, HypoxyProbe), extracellular matrix proteins type I collagen (Abcam), laminin (Sigma), and fibronectin (Sigma), and cancer stem cell markers CD24 (Abcam) and CD133 (Novus Biologicals). Expression of these proteins was detected using a fluorescent secondary antibody, Cy3 conjugated goat anti-rabbit (Ki-67, hypoxia, ECM), FITC conjugated donkey anti-mouse (CD24), or Alexa Fluor 594 conjugated donkey anti-mouse (CD133), obtained from Jackson ImmunoResearch. Nuclei were stained with Hoechst (Life Technologies). Fluorescent images were captured using an inverted fluorescent microscope (Axio Observer, Zeiss) equipped with a high resolution camera (AxioCam $\mathrm{MRm}$, Zeiss) or using a confocal microscope (Fluoview FV1000, Olympus). Image) (NIH) was used for image processing and analysis of Ki-67 expression in spheroid sections. Each spheroid section in captured images was manually divided into elliptical rings; starting from the border toward the center of each section, each ring was 10\% smaller in diameter than its preceding one. The number and size of rings used for analysis was based on the size of spheroid sections. The total fluorescence of each ring was measured and normalized to its area using the integrated density and area measurements in ImageJ.

Preparation of Drug Compounds and Testing: A $50 \times 10^{-3} \mathrm{M}$ stock solution of doxorubicin (Sellekchem) was prepared in dimethyl sulfoxide (DMSO) and stored at $-80^{\circ} \mathrm{C}$ according to the manufacturer's instructions. TH-302 (Santa Cruz Biotechnology) was dissolved in DMSO at a concentration of $44.5 \times 10^{-3} \mathrm{M}$ and stored at $-20^{\circ} \mathrm{C}$ according to the manufacturer's instructions. The desired drug concentrations for experiments were prepared by serial dilution of each stock solution in the complete cell culture medium. Since the drug solutions were directly added to wells containing half of the desired total volume, drug concentrations were prepared at $2 \times$ the desired concentration (for single drug experiments) or $4 \times$ the desired concentration (for combination drug experiments). Cisplatin (Spectrum Chemicals) was dissolved in ultrapure sterile water at a stock concentration of $2 \mathrm{mg} \mathrm{mL}^{-1}$, which was then serially diluted to $2 \times$ working concentrations for the drug test against MDA-MB-157 TNBC spheroids.

After MDA-MB-157 spheroid formation in ATPS at $24 \mathrm{~h}$ of culture (day 1 ), $30 \mu \mathrm{L}$ of cell culture medium was directly added to the wells already containing the PEG phase solution. This addition of the medium disrupted the initial concentrations of PEG and DEX, causing a single phase solution of medium with small residues of polymers. After $72 \mathrm{~h}$ of spheroid culture (day 3 ), $30 \mu \mathrm{L}$ of medium was removed from each well using a multichannel pipette. Then, $30 \mu \mathrm{L}$ of drug solutions at varying concentrations (prepared at $2 \times$ the desired concentrations) was added to wells for single drug testing with doxorubicin or cisplatin. For combination drug testing with doxorubicin and $\mathrm{TH}-302,15 \mu \mathrm{L}$ of each drug solution at varying concentrations (prepared at $4 \times$ the desired concentrations) was added to wells. Wells containing control (nontreated) spheroids received $30 \mu \mathrm{L}$ of fresh medium. Spheroids were incubated for $48 \mathrm{~h}$, and their viability was evaluated using the PrestoBlue assay.

q-PCR Analysis with Spheroids: MDA-MB-157 cells cultured as a monolayer and spheroids of $1.5 \times 10^{4}$ and $1.0 \times 10^{5}$ cells were lysed on the third day of culture using a Total RNA Kit (TRK) lysis buffer (Omega Biotek) and homogenized by passing through homogenizer mini columns (Omega Biotek). Total RNA was isolated from the samples using an RNA isolation kit (Omega Biotek). DNA was removed using RNasefree DNase (Omega Biotek). Purity and concentration of isolated RNA was assessed using optical density (OD) 260/280 spectrophotometry (Synergy H1M, Biotek instruments). cDNA was synthesized from $1 \mu \mathrm{g}$ of total RNA using random hexamer primers (Roche). Real time q-PCR was performed in a LightCycler 480 instrument II using a SYBR Green Master Mix (Roche). Briefly, $50 \mathrm{ng}$ of cDNA was combined with the primer and the SYBR green Master Mix to a final volume of $15 \mu \mathrm{L}$. The reactions were pre-incubated at $95^{\circ} \mathrm{C}$ for $5 \mathrm{~min}$ followed by 45 cycles of amplification, i.e., at $95{ }^{\circ} \mathrm{C}$ for $10 \mathrm{~s}$, at $60^{\circ} \mathrm{C}$ for $10 \mathrm{~s}$, and at $72{ }^{\circ} \mathrm{C}$ for $10 \mathrm{~s}$. Specific primer sequences for all the genes investigated are listed in Table SI-1 in the Supporting Information. Expression levels of mRNA for different gene markers of CSCs and hypoxia were calculated relative to $\beta$-actin and hypoxanthine phosphoribosyltransferase (HPRT) using the $\Delta \Delta C_{t}$ method. The fold change in mRNA expression was determined according to the $2^{-\Delta \Delta \mathrm{Ct}}$ method. Statistical analysis was performed between the larger and smaller spheroid fold changes using a Student's $t$-test in Microsoft Excel software.

\section{Supporting Information}

Supporting Information is available from the Wiley Online Library or from the author.

\section{Acknowledgements}

The work was supported by National Institutes of Health (R21CA182333), Ohio Third Frontier (TECG20140954), and National Science Foundation (1264562). The authors thank Ms. Ashley E. Mohrman for helping with confocal microscopy.

Received: June 17, 2016

Revised: August 3, 2016

Published online: September 7, 2016

[1] X. Xu, M. C. Farach-Carson, X. Jia, Biotechnol. Adv. 2014, 32, 1256.

[2] I. J. Fidler, Nat. Rev. Cancer 2003, 3, 1 .

[3] J. E. Visvader, Nature 2011, 469, 314.

[4] O. Trédan, C. M. Galmarini, K. Patel, I. F. Tannock, J. Natl. Cancer Inst. 2007, 99, 1441.

[5] B. A. Teicher, Cancer Metastasis Rev. 1994, 13, 139.

[6] H. Lu, D. Samanta, L. Xiang, H. Zhang, H. Hu, I. Chen, J. W. Bullen, G. L. Semenza, Proc. Natl. Acad. Sci. USA 2015, 112, E4600.

[7] A. Carnero, M. Lleonart, Insid. Cell 2016, 1, 96.

[8] G. L. Semenza, Trends Pharmacol. Sci. 2012, 33, 207.

[9] G. L. Semenza, Cell 2012, 148, 399.

[10] N. Rohwer, T. Cramer, Drug Resist. Updates 2011, 14, 191.

[11] F. Pampaloni, E. G. Reynaud, E. H. K. Stelzer, Nat. Rev. Mol. Cell Biol. 2007, 8, 839.

[12] X. Yang, S. K. Sarvestani, S. Moeinzadeh, X. He, E. Jabbari, Tissue Eng. Part A 2013, 19, 669.

[13] G. H. Lee, J. S. Lee, X. Wang, S. H. Lee, Adv. Healthcare Mater. 2016, 5,56 .

[14] S. L. Ham, R. Joshi, P. S. Thakuri, H. Tavana, Exp. Biol. Med. 2016, 241, 939.

[15] R. Agarwal, P. Jurney, M. Raythatha, V. Singh, S. V Sreenivasan, L. Shi, K. Roy, Adv. Healthcare Mater. 2015, 4, 2269.

[16] V. Guarneri, M. V. Dieci, P. Conte, Drugs 2013, 73, 1257.

[17] E. Atefi, J. A. Mann, H. Tavana, Langmuir 2014, 30, 9691.

[18] E. Atefi, R. Joshi, J. A. Mann, H. Tavana, ACS Appl. Mater. Interfaces 2015, 7, 21305

[19] H. Tavana, B. Mosadegh, S. Takayama, Adv. Mater. 2010, 22,2628

[20] S. Lemmo, S. Nasrollahi, H. Tavana, Biotechnol. J. 2014, 9, 426.

[21] S. L. Ham, S. Nasrollahi, K. N. Shah, A. Soltisz, S. Paruchuri, Y. H. Yun, G. D. Luker, A. Bishayee, H. Tavana, Integr. Biol. 2015, 7, 792.

[22] N. Lall, C. J. Henley-Smith, M. N. De Canha, C. B. Oosthuizen, D. Berrington, Int. J. Microbiol. 2013, 2013, 420601.

[23] S. Lemmo, E. Atefi, G. D. Luker, H. Tavana, Cell. Mol. Bioeng. 2014, 7, 344.

[24] M. Boisserie-Lacroix, G. Mac Grogan, M. Debled, S. Ferron, M. Asad-Syed, V. Brouste, S. Mathoulin-Pelissier, G. HurteventLabrot, Diagn. Interv. Imaging 2012, 93, 183. 
[25] M. van Dijk, S. a. Göransson, S. Strömblad, Exp. Cell Res. 2013, 319, 1663.

[26] T. Oskarsson, Breast 2013, 22, S66.

[27] N. Cordes, M. A. Blaese, L. Plasswilm, H. P. Rodemann, D. Van Beuningen, Int. J. Radiat. Biol. 2003, 79, 709.

[28] W. Wilson, M. Hay, Nat. Rev. Cancer 2011, 11, 393.

[29] A. I. Minchinton, I. F. Tannock, Nat. Rev. Cancer 2006, 6, 583.

[30] A. M. Shannon, D. J. Bouchier-Hayes, C. M. Condron, D. Toomey, Cancer Treat. Rev. 2003, 29, 297.

[31] C. Ward, S. P. Langdon, P. Mullen, A. L. Harris, D. J. Harrison, C. T. Supuran, I. H. Kunkler, Cancer Treat. Rev. 2013, 39, 171.

[32] F. W. Hunter, H.-L. Hsu, J. Su, S. M. Pullen, W. R. Wilson, J. Wang, Mol. Cancer Ther. 2014, 13, 2501.

[33] J. Brown, W. Wilson, Nat. Rev. Cancer 2004, 4, 437.

[34] N. Aomatsu, M. Yashiro, S. Kashiwagi, H. Kawajiri, T. Takashima, M. Ohsawa, K. Wakasa, K. Hirakawa, BMC Cancer 2014, 14, 400.

[35] E. Y. Tan, M. Yan, L. Campo, C. Han, E. Takano, H. Turley, I. Candiloro, F. Pezzella, K. C. Gatter, E. K. A. Millar, S. A. O'Toole, C. M. McNeil, P. Crea, D. Segara, R. L. Sutherland, A. L. Harris, S. B. Fox, Br. J. Cancer 2009, 100, 405.

[36] A. El Guerrab, R. Zegrour, C. C. Nemlin, F. Vigier, A. Cayre, F. Penault-Llorca, F. Rossignol, Y. J. Bignon, PLoS One 2011, 6, 1.

[37] A. K. McClendon, J. L. Dean, D. B. Rivadeneira, J. E. Yu, C. A. Reed, E. Gao, J. L. Farber, T. Force, W. J. Koch, E. S. Knudsen, Cell Cycle 2012, 11, 2747.

[38] N. Goda, H. E. Ryan, B. Khadivi, W. McNulty, R. C. Rickert, R. S. Johnson, Mol. Cell. Biol. 2003, 23, 359.

[39] R. Sullivan, G. C. Paré, L. J. Frederiksen, G. L. Semenza, C. H. Graham, Mol. Cancer Ther. 2008, 7, 1961.

[40] M. Achison, T. R. Hupp, Oncogene 2003, 22, 3431.

[41] J. T. Erler, C. J. Cawthorne, K. J. Williams, M. Koritzinsky, B. G. Wouters, C. Wilson, C. Miller, C. Demonacos, I. J. Stratford, C. Dive, Mol. Cell. Biol. 2004, 24, 2875.

[42] J. Xie, Y. Xiao, X. Zhu, Z. Ning, H. Xu, H. Wu, Med. Oncol. 2016, 33, 42.

[43] C. Holohan, S. Van Schaeybroeck, D. B. Longley, P. G. Johnston, Nat. Rev. Cancer 2013, 13, 714.

[44] F. Meng, J. W. Evans, D. Bhupathi, M. Banica, L. Lan, G. Lorente, J. X. Duan, X. Cai, A. M. Mowday, C. P. Guise, A. Maroz, R. F. Anderson, A. V Patterson, G. C. Stachelek, P. M. Glazer, M. D. Matteucci, C. P. Hart, Mol. Cancer Ther. 2012, 11, 740.

[45] J. D. Sun, Q. Liu, D. Ahluwalia, W. Li, F. Meng, Y. Wang, D. Bhupathi, A. S. Ruprell, C. P. Hart, Cancer Biol. Ther. 2015, 16, 438.

[46] F. Meng, D. Bhupathi, J. D. Sun, Q. Liu, D. Ahluwalia, M. D. Matteucci, C. P. Hart, BMC Cancer 2015, 15, 422.

[47] T. Chou, Pharmacol. Rev. 2006, 58, 621.

[48] A. Tyagi, C. Agarwal, D. Chan, R. Agarwal, Oncol. Rep. 2004, 11, 493.

[49] J. D. Sun, D. Ahluwalia, Q. Liu, W. Li, Y. Wang, F. Meng, D. Bhupathi, M. D. Matteucci, C. P. Hart, Am. J. Cancer Res. 2015, $5,2139$.

[50] S. G. J. A. Peeters, C. M. L. Zegers, R. Biemans, N. G. Lieuwes, R. G. P. M. Van Stiphout, A. Yaromina, J. D. Sun, C. P. Hart, A. D. Windhorst, W. Van Elmpt, L. J. Dubois, P. Lambin, Clin. Cancer Res. 2015, 21, 2984.

[51] S. P. Chawla, L. D. Cranmer, B. A. Van Tine, D. R. Reed, S. H. Okuno, J. E. Butrynski, D. R. Adkins, A. E. Hendifar, S. Kroll, K. N. Ganjoo, J. Clin. Oncol. 2014, 32, 3299.

[52] O. J. Arola, A. Saraste, K. Pulkki, M. Kallajoki, M. Parvinen, L.-M. Voipio-Pulkki, Cancer Res. 2000, 60, 1789.

[53] Y.-W. Zhang, J. Shi, Y.-J. Li, L. Wei, Arch. Immunol. Ther. Exp. 2009, $57,435$.

[54] H. Kobayashi, Y. Takemura, T. Ohnuma, Cancer Chemother. Pharmacol. 1992, 31, 6 .
[55] Y. Takemura, H. Kobayashi, H. Miyachi, K. Hayashil, S. Sekiguchil, T. Ohnuma, Cancer Chemother. Pharmacol. 1991, 27, 417.

[56] T. Ohnuma, H. Arkin, J. F. Holland, Br. J. Cancer 1986, 54, 415.

[57] B. Keith, M. C. Simon, Cell 2007, 129, 465.

[58] J. Heddleston, Z. Li, J. Lathia, S. Bao, A. Hjelmeland, J. Rich, Br. J. Cancer 2010, 102, 789.

[59] B. Muz, P. de la Puente, F. Azab, M. Luderer, A. K. Azab, Blood Cancer J. 2014, 4, e262.

[60] H. Yao, N. Liu, M. C. Lin, J. Zheng, Cancer Lett. 2016, 379, 213.

[61] A. Dhawan, S. A. Madani Tonekaboni, J. H. Taube, S. Hu, N. Sphyris, S. A. Mani, M. Kohandel, Sci. Rep. 2016, 6, 18074.

[62] P. Subarsky, R. Hill, Clin. Exp. Metastasis 2003, 20, 237.

[63] S. Vinogradov, X. Wei, Nanomedicine 2012, 7, 597.

[64] J. P. Medema, Nat. Cell Biol. 2013, 15, 338.

[65] M. Al-Hajj, M. S. Wicha, A. Benito-Hernandez, S. J. Morrison, M. F. Clarke, Proc. Natl. Acad. Sci. USA 2003, 100, 3983.

[66] L. L. C. Marotta, V. Almendro, A. Marusyk, M. Shipitsin, J. Schemme, S. R. Walker, N. Bloushtain-qimron, J. J. Kim, S. a. Choudhury, R. Maruyama, Z. Wu, M. Gönen, L. a. Mulvey, M. O. Bessarabova, S. J. Huh, S. J. Silver, J. Clin. Invest. 2011, 121, 2723.

[67] M. a. H. Ahmed, M. a. Aleskandarany, E. a. Rakha, R. Z. a. Moustafa, A. Benhasouna, C. Nolan, A. R. Green, M. Ilyas, I. O. Ellis, Breast Cancer Res. Treat. 2012, 133, 979.

[68] Y. Lin, Y. Zhong, H. Guan, X. Zhang, Q. Sun, J. Exp. Clin. Cancer Res. 2012, 31, 59.

[69] F. Ma, H. Li, H. Wang, X. Shi, Y. Fan, X. Ding, C. Lin, Q. Zhan, H. Qian, B. Xu, Cancer Lett. 2014, 353, 153.

[70] D. R. Pattabiraman, R. A. Weinberg, Nat. Rev. Drug Discov. 2014, 13, 497.

[71] M. L. Huebschman, N. L. Lane, H. Liu, V. R. Sarode, J. L. Devlin, E. P. Frenkel, Breast Cancer Targets Ther. 2015, 7, 231.

[72] Y. J. Liu, D. Shen, X. Yin, P. Gavine, T. Zhang, X. Su, P. Zhan, Y. Xu, J. Lv, J. Qian, C. Liu, Y. Sun, Z. Qian, J. Zhang, Y. Gu, X. Ni, Br. J. Cancer 2014, 110, 1169.

[73] G. Kristiansen, M. Sammar, P. Altevogt, J. Mol. Histol. 2004, 35, 255.

[74] Z. Wang, Q. Shi, Z. Wang, Y. Gu, Y. Shen, M. Sun, M. Deng, H. Zhang, J. Fang, S. Zhang, F. Xie, Pathol. Res. Pract. 2011, 207, 505.

[75] S. Thomas, M. A. Harding, S. C. Smith, J. B. Overdevest, M. D. Nitz, H. F. Frierson, S. A. Tomlins, G. Kristiansen, D. Theodorescu, Cancer Res. 2012, 72, 5600.

[76] A. Imaizumi, H. Onishi, A. Yamasaki, M. Kawamoto, M. Umebayashi, T. Morisaki, K. Hasumi, Anticancer Res. 2016, 36, 653.

[77] G. Kristiansen, K.-J. Winzer, E. Mayordomo, J. Bellach, K. Schluns, C. Denkert, E. Dahl, C. Pilarsky, P. Altevogt, H. Guski, M. Dietel, Clin. Cancer Res. 2003, 9, 4906.

[78] E. Mylona, I. Giannopoulou, E. Fasomytakis, A. Nomikos, C. Magkou, P. Bakarakos, L. Nakopoulou, Hum. Pathol. 2008, 39, 1096.

[79] P. Sansone, C. Ceccarelli, M. Berishaj, Q. Chang, V. K. Rajasekhar, F. Perna, R. L. Bowman, M. Vidone, L. Daly, J. Nnoli, D. Santini, M. Taffurelli, N. N. C. Shih, M. Feldman, J. J. Mao, C. Colameco, J. Chen, A. DeMichele, N. Fabbri, J. H. Healey, M. Cricca, G. Gasparre, D. Lyden, M. Bonafé, J. Bromberg, Nat. Commun. 2016, 7, 10442.

[80] N. Kapucuoğlu, K. Bozkurt, S. Başpınar, M. Koçer, H. Eroğlu, R. Akdeniz, M. Akçil, Pathol. Res. Pract. 2015, 211, 740.

[81] D. Zhang, B. Sun, X. Zhao, Y. Ma, R. Ji, Q. Gu, X. Dong, J. Li, F. Liu, X. Jia, X. Leng, C. Zhang, R. Sun, J. Chi, Mol. Cancer 2014, 13, 207.

[82] X. Lv, Y. Wang, Y. Song, X. Pang, H. Li, Oncol. Lett. 2016, 11, 1750. 
[83] D. G. Kim, K. H. Kim, Y. J. Seo, H. Yang, E. G. Marcusson, E. Son, K. Lee, J. K. Sa, H. W. Lee, D.-H. Nam, Oncotarget 2016, DOI: 10.18632/oncotarget.8837.

[84] C. Bock, C. Kuhn, N. Ditsch, R. Krebold, S. Heublein, D. Mayr, S. Doisneau-Sixou, U. Jeschke, J. Cancer Res. Clin. Oncol. 2014, 140, 1873.

[85] A. leni, G. Giuffrè, V. Adamo, G. Tuccari, Anticancer Res. 2011, 31, 1315.

[86] S. K. Swaminathan, E. Roger, U. Toti, L. Niu, J. R. Ohlfest, J. Panyam, J. Controlled Release 2013, 171, 280.

[87] C. H. Stuelten, S. D. Mertins, J. I. Busch, M. Gowens, D. A. Scudiero, M. W. Burkett, K. M. Hite, M. Alley, M. Hollingshead, R. H. Shoemaker, J. E. Niederhuber, Stem Cells 2010, 28, 649.

[88] I. Ben-porath, M. W. Thomson, V. J. Carey, R. Ge, W. George, A. Regev, R. a. Weinberg, Nat. Genet. 2008, 40, 499.

[89] O. Leis, A. Eguiara, E. Lopez-Arribillaga, M. Alberdi, S. Hernandez-Garcia, K. Elorriaga, A. Pandiella, R. Rezola, A. Martin, Oncogene 2012, 31, 1354.
[90] M. Piva, G. Domenici, O. Iriondo, R. Miriam, I. Zabalza, R. Kypta, V. Comaills, I. Barredo, a. L. Jose, M. M. Vivanco, EMBO Mol. Med. 2014, 6, 66 .

[91] J. Mathieu, Z. Zhang, W. Zhou, A. J. Wang, J. M. Heddleston, C. M. A. Pinna, A. Hubaud, B. Stadler, M. Choi, M. Bar, M. Tewari, A. Liu, R. Vessella, R. Rostomily, D. Born, M. Horwitz, C. Ware, C. A. Blau, M. A. Cleary, J. N. Rich, H. Ruohola-Baker, Cancer Res. 2011, 71, 4640.

[92] C. Zhang, D. Samanta, H. Lu, J. W. Bullen, H. Zhang, I. Chen, X. He, G. L. Semenza, Proc. Natl. Acad. Sci. 2016, 113, E2047.

[93] H. Tavana, A. Jovic, B. Mosadegh, Q. Y. Lee, X. Liu, K. E. Luker, G. D. Luker, S. J. Weiss, S. Takayama, Nat. Mater. 2009, $8,736$.

[94] S. L. Ham, E. Atefi, D. Fyffe, H. Tavana, J. Vis. Exp. 2015, e52754.

[95] N. Timmins, L. Nielsen, Methods Mol. Med. 2007, 140, 141. 